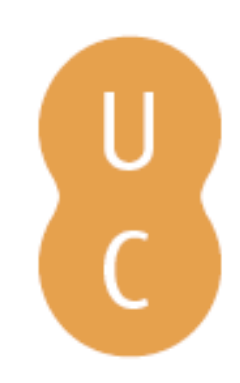

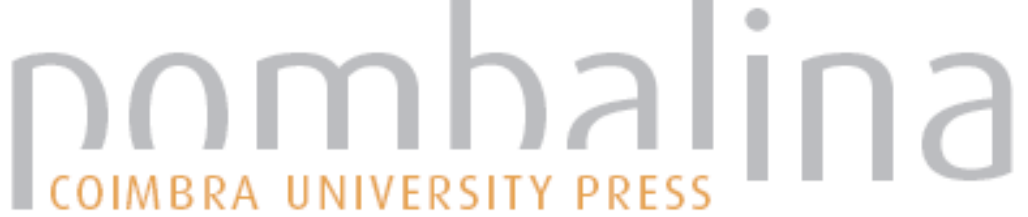

\section{A fundamentação educativa em Álvaro Vieira Pinto: formação humana e historicidade no âmago do real}

Autor(es): $\quad$ Peixoto Filho, José Pereira; Costa, Danilo Svágera da

Publicado por: Imprensa da Universidade de Coimbra

URL

persistente: URI:http://hdl.handle.net/10316.2/41297

DOI: $\quad$ DOI:https://doi.org/10.14195/978 $\quad$ 289 26 1326-0_8

Accessed : $\quad$ 26-Apr-2023 14:45:21

A navegação consulta e descarregamento dos títulos inseridos nas Bibliotecas Digitais UC Digitalis, UC Pombalina e UC Impactum, pressupõem a aceitação plena e sem reservas dos Termos e Condições de Uso destas Bibliotecas Digitais, disponíveis em https://digitalis.uc.pt/pt-pt/termos.

Conforme exposto nos referidos Termos e Condições de Uso, o descarregamento de títulos de acesso restrito requer uma licença válida de autorização devendo o utilizador aceder ao(s) documento(s) a partir de um endereço de IP da instituição detentora da supramencionada licença.

Ao utilizador é apenas permitido o descarregamento para uso pessoal, pelo que o emprego do(s) título(s) descarregado(s) para outro fim, designadamente comercial, carece de autorização do respetivo autor ou editor da obra.

Na medida em que todas as obras da UC Digitalis se encontram protegidas pelo Código do Direito de Autor e Direitos Conexos e demais legislação aplicável, toda a cópia, parcial ou total, deste documento, nos casos em que é legalmente admitida, deverá conter ou fazer-se acompanhar por este aviso. 


\title{
8. A FUNDAMENTAÇÃO EDUCATIVA EM ÁLVARO VIEIRA PINTO: FORMAÇÃO HUMANA E HISTORICIDADE NO ÂMAGO DO REAL
}

\author{
José Pereira Peixoto Filho 21 \\ Danilo Svágera da Costa 22
}

\begin{abstract}
Resumo
Este estudo analisa a fundamentação educacional proposta pelo filósofo contemporâneo brasileiro Álvaro Vieira Pinto. Para tanto, discute-se as noções centrais presentes em sua obra "Sete Lições sobre Educação de Adultos" (1982), tais como: consciência, ingenuidade e criticismo, bem como a enfática relação da educação com a historicidade e a formação humana. Como proposta investigativa, iremos primeiramente abordar as motivações que levaram Álvaro a mudar o foco investigativo de suas obras, oferecendo-nos uma guinada da filosofia para uma temática educacional. No segundo momento, investigaremos as noções centrais da concepção educativa segundo o filósofo, visando uma explicação conceitual dos principais vocábulos
\end{abstract}

21 Doutor em Educação pela Universidade Federal do Rio de Janeiro (UFRJ). Programa de Pós-Graduação em Educação - Universidade do Estado de Minas Gerais.

22 Mestre em Educação pela Universidade do Estado de Minas Gerais (UEMG). Programa de Pós-Graduação em Educação - Universidade do Estado de Minas Gerais. 
utilizados para a constituição de uma Filosofia da Educação proposta pelo pensador. Em última instância, reiteramos como objetivo a recolocação das ideias do supracitado autor em debate, perfazendo as palavras de Paulo Freire ao incentivar o estudo de Álvaro (Freire, 1967).

\begin{abstract}
This study analyses the educational foundation planned by the Brazilian contemporary philosopher Álvaro Vieira Pinto. Therefore it discusses the central ideas present in his work "Sete Lições sobre Educação de Adultos" ("Seven Lessons on Adult Education", 1982), such as: awareness, ingenuity and criticism and, also, the emphatic relationship between education and the historicity and the human training/education. As investigative proposal, we will first address the reasons that led Álvaro to change the investigative focus of his works, a change from philosophy to educational themes. In the second phase, we will explore central notions of the educational concept supported by the philosopher, seeking a conceptual explanation of the key words used for the establishment of a Philosophy of Education proposed by the thinker. Finally, we reinforce the objective of replace ideas of the cited author, putting into practice the words of Paulo Freire to encourage the study of Álvaro (Freire, 1967).
\end{abstract}




\section{Introdução}

A compreensão de um dado período histórico, de suas peculiaridades e de sua conjuntura perpassa por uma série de fatores amplos, dinâmicos e orgânicos que exigem demasiada atenção do intérprete que almeje empreender uma discussão no âmbito da história da educação. Com efeito, ao dissertamos acerca de qualquer período, inúmeras questões se colocam, defrontando-nos com problemas epistemológicos que exigem cautela para evitarmos localismos e fragmentações prejudiciais a todo percurso investigativo. Sobre essa dificuldade inerente às investigações, Schaff pontua

Agora que entramos no âmago do assunto, o conhecimento histórico, comecemos por confrontar duas das maiores escolas de pensamento [...]. Trata-se, por um lado, do positivismo, que atesta que o conhecimento histórico é possível como reflexo fiel, puro de todo fator subjetivo, dos fatos do passado: por outro lado, do presentismo, variante atualmente mais em voga do relativismo subjetivista, que nega que tal conhecimento seja possível e considera a história como uma projeção do pensamento e dos interesses presentes sobre o passado. (Schaff, 1995, p. 101)

Tomando esse prelúdio como base, nosso pôster possui como objetivo expor os pontos nevrálgicos da concepção educacional de Álvaro Vieira Pinto, filósofo brasileiro integrante do Instituto Superior de Estudos Brasileiros e grande colaborador no pensamento educacional de Paulo Freire ${ }^{23}$. Para tanto, dividiremos nosso texto

23 Não iremos explorar essa afirmação em sua amplitude neste texto por questões limítrofes temporais. Cabe-nos, contudo, ressaltar que o nome de Álvaro Vieira é citado por Freire como "mestre brasileiro" (Freire, 1967) e que o educador possuía estreito vínculo com as ideias vieiristas. O assunto em sua completude está sendo abordado em minha dissertação, cujo título é Da consciência ingênua à Formação do criticismo: o diálogo conceitual entre Álvaro Vieira Pinto e Paulo Freire, a ser publicada em breve. 
em três partes, a saber: na primeira, exporemos brevemente as motivações vieiristas no estudo da temática da Filosofia da Educação; na segunda parte, elucidaremos a concepção de educação, tomando como base suas principais características, a partir das investigações contidas na obra "Sete Lições sobre Educação de Adultos" (1982); na parte conclusiva, levantaremos questões relativas à nossa investigação, com o intuito de perfazermos o ato reflexivo.

\section{Álvaro Vieira Pinto e a guinada para a educação}

Álvaro Vieira Pinto, filósofo nascido em Campos (RJ) no ano de 1909, possui uma trajetória intelectual calcada em expor filosoficamente a realidade e estrutura do Brasil. Como diretor do Departamento de Filosofia do Instituto Superior de Estudos Brasileiros, órgão criado no governo Café Filho para refletir acerca dos problemas nacionais, escreve aquela que seria considerada a suma do pensamento do Instituto (Cortes, 1997): "Consciência e Realidade Nacional” (1960), cujo intuito era dissecar fenomenologicamente a noção de consciência, tomando como base suas duas modalidades - ingênua e crítica - e fundando, ao mesmo tempo, um coeso sistema categorial filosófico.

Com o passar dos anos dentro do Instituto, porém, o autor desloca sua centralidade de interesse (a fenomenologia e outros temas puramente conceituais - filosóficos) para a educação. Uma pergunta, portanto, se abre: por qual motivo Álvaro, que estava empenhado em um sistema estritamente filosófico, passa a interessar-se na discussão educacional? Estaria o autor dando uma guinada - uma espécie de revolução copernicana, referindo-nos a Kant - em seus temas de interesses, excluindo, pois, a filosofia?

Algumas respostas se mostram como possíveis. Primeiramente, podemos perceber que a educação faz parte de seu projeto nacio- 
nalista, sendo a condição de possibilidade para a nação transcender seu status de subdesenvolvimento. Tal hipótese é mencionada no discurso de 1956 (Vieira Pinto, 1956), sugerindo uma conexão entre as obras/temas desenvolvidas pelo autor.

Tentando também responder a questão, Roux (1990) argumenta que a educação seria uma conseqüência natural da exposição acerca da consciência crítica (Roux, 1990, p. 186), haja visto que Vieira havia percebido o homem como ser pensante e, dessa forma, modificador do mundo e de si mesmo - desempenhando a educação forte papel nessa percepção.

Renato Ramos Martini, por sua vez, defende a tese de que Vieira, tal como outros intelectuais provindos das cadeiras isebianas, passaram progressivamente a abandonar o tema da política em suas investigações e, paulatinamente, começaram a se interessar pelo tema da cultura e educação.

Sintomático em relação à natureza do instituto, é o fato de que apesar de muitos dos seus integrantes, terem flertado com a política e engrossado a fileira de partidos políticos, o Instituto nunca assumiu de fato uma relação dependente com a política, e na opção entre o exercício público e a atividade intelectual, a escolha sempre pendeu para o lado da segunda opção [cultura]. (Martini, 2009, p. 59)

Esse interesse pela cultura se dava, sobretudo, por dois fatores: de um lado, era um débito com o ministério ao qual estavam vinculados (Ministério da Educação e Cultura); por outro, representava uma maior autonomia frente ao governo, o que coloca em xeque uma concepção histórica de que os pensadores do ISEB faziam, em seu todo, a propaganda para um governo.

Indiferente da posição escolhida acerca dos motivadores vieiristas em abordar a educação, fato é que se torna inegável a preocupação 
do autor com o tema, sobretudo ao pensar esse campo como a condição de possibilidade de realização da consciência crítica (e consequente abandono de uma visão miraculosa ou ingênua do mundo). Sobretudo, como assinala Martini, é dessa preocupação com a educação que trará uma interpretação da temática que aproximará nosso autor com Paulo Freire.

Talvez seja no binômio cultura e educação que se assentam os pilares da consciência crítica de Viera Pinto. A educação é ressaltada várias vezes por Vieira Pinto, como tendo alta prioridade no tema do desenvolvimento nacional. Educação entendida não como processo formal desligada da realidade do trabalhador, daí sua proximidade com Paulo Freire. (Martini, 2009, p. 65)

Um fato que não pode ser descartado é que, no interior da obra que escreve sobre educação, Vieira não abandona sua formação filosófica nem seus conceitos filosóficos desenvolvidos anteriormente. Prova disso é o caráter filosófico sistemático que acompanhará seu escrito educacional, bem como a importância dos conceitos de ingenuidade e criticismo, herdados de sua obra de 1960.

\section{O conceito de educação em Álvaro Vieira Pinto}

Lançado somente em 1982, a partir de suas conferências realizadas no Chile nos anos sessenta, o livro "Sete Lições sobre Educação de Adultos ${ }^{24 "}$ expressa sobremaneira a visão do autor acerca do âmbito educativo. Em entrevista cedida a Dermeval Saviani, utilizada como abertura do livro em questão, Vieira nos diz que sua intenção na publicação da obra era tecer comentários a respeito

${ }^{24}$ Doravante utilizaremos, quando necessário, da sigla SL para aludirmos a obra. 
da teoria e da prática em educação, tomando como base seus elementos constitutivos - educador e educando (Vieira Pinto, 1982, p. 23). Afirma também que, embora deseje lançar um livro especificamente sobre a arte da pedagogia (na qual ele desenvolveria o que denominava pedagogia filosófica), até aquele momento ele somente tinha elaborado observações preliminares e críticas sobre a prática da educação. Neste viés, podemos afirmar que a obra de 1982 será uma exposição de uma Filosofia da Educação, ao abordar os conceitos inerentes ao fazer educativo.

O primeiro passo de Álvaro, ao iniciar sua exposição acerca da educação, é delimitar o campo a ser investigado. Valendo-se de um procedimento tipicamente atribuído a Sócrates, o movimento de definição conceitual, seu objetivo na primeira parte do livro recairá na tentativa de uma restrição investigativa, prezando por conduzir o leitor diante de sua exposição subsequente. Para tanto, utilizará a unidade básica da filosofia, o conceito:

O filósofo é o amigo do conceito, ele é conceito em potência. Quer dizer que a filosofia não é uma simples arte de formar, de inventar ou de fabricar conceitos, pois os conceitos não são necessariamente formas, achados ou produtos. A filosofia, mais rigorosamente, é a disciplina que consiste em criar conceitos. O amigo seria o amigo de suas próprias criações? Ou então é o ato do conceito que remete à potência do amigo, na unidade do criador e de seu duplo? (Deleuze e Guattari, 1992, p. 12).

Segundo Vieira, podemos tomar a educação de duas formas: de um lado, chamado de sentido restrito, a educação seria o ensino "às fases infantil e juvenil da vida do ser humano" (Vieira Pinto, 1982, p. 29), embora essa definição, para o autor, se mostre errônea por não conter a real essência educativa. Por outro lado, denominado de sentido amplo ou autêntico, "a educação diz respeito a existência 
humana em toda a sua duração e em todos os seus aspectos", sendo um "processo pelo qual a sociedade forma seus membros à sua imagem e em função de seus interesses". (Viera Pinto, 1982, p. 29). Essa definição, que amplia drasticamente o modo de ver a educação, exige uma caracterização sociológica e filosófica de seus aspectos, passando pela abordagem da educação de adultos.

Dessa definição, o autor continua sua exposição expondo as características concernentes ao campo estudado. Atribui, para tanto, doze caracteres visando lapidar o conceito. São eles:

1. A educação é um processo (histórico): representa a história do indivíduo e, ao mesmo tempo, a história de sua comunidade em andamento. Não pode se resumir, portanto, numa noção exclusivamente individual, pois abarca um todo social em curso, devir, sendo compreensível à luz da mudança - e não numa concepção estática de realidade.

2. A educação é um fato existencial: refere-se a maneira como o homem se vê, existencialmente, perante os outros, se constituindo como homem. Nesse aspecto, relaciona-se à noção de intencionalidade, por depender de um conceito ideal de homem em sua essência. "Este modelo, contudo, é um dado de consciência de alguém (...) que está num dado tempo, num espaço, em definida posição social" (Vieira Pinto, 1982, p. 35). Na forma ingênua a educação considera a transformação do não homem em homem. Na forma crítica, concebe como um diálogo entre seres pensantes, surgindo o conceito de responsabilidade educativa.

3. A educação é um fato social, ou seja, é determinada pelos interesses intrínsecos de uma dada sociedade. Desse caractere surge a contradição educativa, que é a conservação de uma determinada estrutura e, ao mesmo tempo, uma intenção de progresso, de ruptura com a presente estrutura. 
4. A educação é um fenômeno cultural: ela transmite um todo cultural ao educando, seja de crenças, valores, hábitos e experiências. Nesse intuito, representa os interesses de um determinado prospecto social.

5. A educação não forma uniformemente: sendo o conjunto de saberes algo extenso, a educação não visa uma uniformidade formativa, mas seleciona grupos para o aprendizado de certos aspectos (alfabetização, por exemplo) em detrimento de outros.

6. A educação relaciona-se com a economia, pois são os aspectos econômicos que determinam e fundamentam as possibilidades de cada etapa cultural. Também é a economia que definirá os meios materiais para a realização efetiva de determinada execução educacional.

7. A educação é teleológica, na medida em que direciona-se para um fim, que é a integração do indivíduo para com a sociedade, visando desempenhar funções.

8. A educação é uma modalidade de trabalho social, ou seja, forma os educandos para o desempenho de uma função; dirige-se a trabalhadores, no caso da educação de adultos; e, paralelamente, o educador é um trabalhador. Depreende-se que, para aprofundar na temática, o conceito de trabalho desempenhe papel fundamental.

9. A educação é um fato de ordem consciente: é um processo determinado pelo grau de consciência de uma dada sociedade, e objetiva proporcionar ao educando um grau de consciência de si e do mundo - até o alcance de uma autoconsciência (consciência pautada pelo criticismo).

10. É um processo exponencial, pois, quanto mais se educa, mais há a necessidade de continuar no processo investigativo. Dessa característica surge a noção de educação como um processo contínuo e inacabado. 
11. A educação é por essência concreta: embora possa ser compreendida a priori, kantianamente dizendo, ela deve ser investigada a partir de sua realização objetiva, submetida a bases materiais.

12. A educação é naturalmente contraditória, pois implica conservação e criação do saber. Dessa forma, não serão categorias formais da lógica clássica aristotélica que conseguirá explicar sua situação, mas sim a dialética.

A partir dos doze caracteres da educação, Vieira oferece-nos uma conceituação pormenorizada do que entende pelo fenômeno educativo. Podemos perceber, sobremaneira, que o filósofo enfatiza, no decorrer da exposição, duas características essenciais, que perpassam por todos os doze itens: a historicidade e a formação humana. Sobre tais aspectos o autor nos diz:

A historicidade pertence a essência da educação. Não se confunde com a temporalidade (que é o fato de haver tido um passado), porém se define por sua essencial transitividade (o fato de haver um futuro). Por isso, a história da educação favorece a compreensão do processo educacional; é indispensável, mas não a esgota. Porque o exercício da tarefa educativa conduz a própria modificação. (Vieira Pinto, 1982, p. 34)

Se Álvaro elege a historicidade como a essência da educação, a formação do homem (como ser cônscio de si e da realidade) também é eleita com função análoga. Com efeito, podemos perceber diante do exposto como a formação do sujeito (seja do educando, seja do educador) é colocada na centralidade do proposto vieirista. Sobre esse tema, Antônio Marques do Vale ressalta:

Ele insistiu de início, que a educação tinha caráter social e, portanto, histórico; se a sociedade fosse democrática, os interesses 
dominantes teriam de ser os do povo. Assim, educação era um fato humano, encontro entre consciências livres, encontro dos educadores entre si e com os alunos. Em preparação permanente o educador-junto com o filosofo e o sociólogo - necessitava possuir noção crítica do próprio papel, refletir sobre o significado da vida profissional, as circunstâncias que determinavam a sua missão e a finalidade de sua ação. Tal finalidade tinha de ser nacional: transformar a nação. O educador, como o pedagogo, era chamado a produzir o saber e não a imitar o que em outras nações se produzia. A alienação do mimetismo ou da transplantação não mais se justificava depois de a sociedade ter adquirido suficiente consciência de si. Do ponto de vista antropológico-sociológico, Viera Pinto falava ainda do educador de adultos: como formador da consciência crítica, e o adulto crítico por sua vez, não aceitaria largar o próprio meio para apenas satisfazer-se em ser técnico. $\mathrm{Na}$ verdade, a atividade educadora, eminentemente social, só era válida se o educando admitisse participar dos acontecimentos no seu meio vital. (Do Vale 2006, pp.119-120)

As investigações precedentes a respeito da educação exigem uma diferenciação que, embora apareça relatada no terceiro capítulo de sua obra educacional, somente são completamente compreensíveis à luz de CRN - faço alusão aos conceitos de consciência ingênua e crítica.

Aparecendo como termos centrais na arquitetônica filosófica do autor, os conceitos supracitados adquirem status de importância dentro da visão educacional vieirista, por se apresentarem como modos diferentes de compreender a realidade - e, portanto, a educação (já que é nela que o indivíduo torna-se parte do mundo, espacialmente e historicamente).

No primeiro momento do capítulo 3 de SL, Álvaro sugere-nos uma conceituação rápida de consciência. Segundo o autor, tal se- 
ria uma "representação mental da realidade exterior, do objeto, do mundo, e representação mental de si, do sujeito, autoconsciência" (Vieira Pinto, 1982, p. 59). Podemos perceber que esse conceito que Vieira nos traz identifica-se com o conceito de consciência individual contida em CRN, embora sem apresentar os desdobramentos enunciados na obra anterior (tais como a consciência coletiva e o sentimento geral). Estaria Vieira alterando sua noção de consciência no decorrer de sua trajetória?

Defendemos a posição de que essa opção do autor, em abordar rapidamente o conceito de consciência nas SL, justifica-se pelo seguinte motivo: por tratar de uma obra sobre filosofia da educação e não especificamente de ontologia e epistemologia, tal como a obra de 1960, o filósofo dá preferência à primeira sobre a segunda temática, evitando uma repetição conceitual já elaborada em extensa obra anterior (CRN). Outro ponto defendido é o de que, na medida em que se aproxima da praxis educativa, Vieira paralelamente aborda o conceito de consciência aproximando de noções políticas e existenciais, prezando pela conscientização (ato ou efeito de colocar-se diante da realidade efetiva) e não mais de uma abstração ôntica. Esse movimento é próprio da consciência crítica, sugerindo-nos um despir-se de conceitos abstratos e vinculando-se à realidade.

A mesma rapidez conceitual, utilizada ao abordar o conceito de consciência, ocorre quando o autor aborda suas modalidades específicas. Com efeito, ao referir-se a ingenuidade, detém-se a dizer que 1) não se preocupa com a objetividade nem a historicidade do mundo e 2) não é capaz de uma autoconsciência (autoanálise) fundada nos seus reais determinantes. Ao referir-se, por sua vez, ao criticismo, nos diz: 1) "é a representação mental do mundo exterior e de si, acompanhada da clara percepção dos condicionamentos objetivos (Vieira Pinto, 1982, p. 60) e 2) a capacidade de tornar-se autoconsciência, percebendo a si mesma como real, material, histórica, social e nacional. 
Apesar de a conceituação ser apresentada de forma sucinta - demandando toda a leitura prévia de CRN (e, no nosso caso, a redação da quarta parte do segundo capítulo desta dissertação) - e, em muitos casos, uma ressignificação da consciência crítica como conscientização sobre o real, seus desdobramentos educacionais não correspondem a simplismos.

Inequivocamente, faz parte da consciência ingênua um conjunto de erros, seja estrutural ou conceitual, no âmbito educacional. Aqueles que lidam com a educação de forma ingênua não conseguem solucionar problemas advindos do cotidiano por desconsiderar os fatores determinantes da realidade (tais como historicidade, nacionalidade, fatores sociais, econômicos). São alguns erros da consciência ingênua no tocante a educação, segundo Vieira Pinto:

1. Considerar o educando como ignorante, seja criança ou adulto. Tal erro reside no fato de que o educando já possui um "acervo" de informações ao adentrar na escola, resultado da prática social que já traz consigo no momento histórico anterior.

2. Considerar o educando como puro objeto da educação: "supor que cabe ao educador formar, plasmar o aluno, concebendo-o como massa amorfa" (Vieira Pinto, 1982, p. 61). Esse erro reside na admissão do educando como objeto, sem perceber que se está diante de um sujeito.

3. Ver a educação como transmissão de um conhecimento infinito: nega-se, ao considerar a educação dessa forma, o caráter histórico do conhecimento, além dos já expostos nos pontos 1 e 2 supracitados.

4. A educação como dever moral: segundo Vieira, proceder dessa forma oculta o verdadeiro caráter social da educação, histórico, e atribui-lhe valoração puramente ética.

5. Afirmação da ignorância do educando das classes populares: com efeito, há uma tendência a considerar o educando como 
ignorante (ponto 1 supramencionado), embora Vieira acrescente: há uma tendência em achar a elite como puramente culta, enquanto o "homem do povo" um ser ignorante. Reside, como já dissemos anteriormente, uma falsa concepção tratarmos a realidade dessa forma, pois se o ignorante é aquele que ignora, quem mais ignora o saber do outro a não ser a elite que não acredita no saber do popular?

Evitando uma repetição dos conteúdos acima abordados, podemos dizer que a consciência crítica é, ao olhar de Vieira, a "antítese da ingênua" (Vieira Pinto, 1982, p. 63). Sendo assim, ao conceber a maneira segundo a qual a consciência crítica percebe a educação, Vieira resume em duas proposições: 1) o educando é um sabedor e 2) o educando é um sujeito, e não um objeto.

O embate entre as duas visões de consciência, embora apareça conceitualmente e de forma específica somente na terceira parte da obra SL, está presente em diversos pontos da obra. Com efeito, percebemos que tais se mostram centrais na concepção de educação para o autor, pois vincula-se ao sistema filosófico antes elaborado - em sua obra de 1960.

Podemos dizer, a efeito conclusivo deste movimento, que há um continuísmo entre as obras do autor, sugerindo uma forte concepção de realidade e de filosofia para Álvaro Vieira Pinto.

\section{Conclusão}

Podemos perceber, a partir dos escritos precedentes, que a educação desempenha forte interesse de investigação para Vieira Pinto. Oferecendo-nos uma amálgama entre seus conceitos filosóficos erigidos nas obras precedentes (tais como consciência ingênua e crítica), bem como reflexões provindas da praxis educativa, o autor 
oferece-nos uma coesa fundamentação educacional - permitindo-nos afirmar uma vigorosa e frutífera filosofia da educação a ser abordada.

Apesar deste fato, ainda existe uma carência de obras publicadas com o intuito em abordar tanto a filosofia quanto a noção educacional do autor, ficando muitas vezes restritas em aludir Vieira como um importante personagem histórico aos olhos de Paulo Freire.

Desta forma, e concluindo nosso trabalho, afirmamos a necessidade de recolocar as ideias do filósofo em debate, incentivando um outro olhar acerca dos intelectuais brasileiros e pensando, em última instância, nossa própria realidade nacional.

\section{Referências bibliográficas}

Cortes, N. (2003). Esperança e democracia: as ideias de Álvaro Vieira Pinto. Belo Horizonte: Editora UFMG.

Deleuze, G. \& Guattari, F.(1992). O que é a filosofia? (Trad. Bento Prado Jr. e Alberto Alonso Munoz). Coleção TRANS. Editora 34.

Do vale, A. M. (2006). O ISEB, os intelectuais e a diferença: um diálogo teimoso na educação. São Paulo: UNESP.

Freire, P.(1967). Educação como prática da liberdade. Rio de Janeiro: Paz e Terra. Martini, R. R.(2009). Os intelectuais do iseb, cultura e educação nos anos cinqüenta e sessenta. Revista AURORA, 3(5).

Pinto, Á.V.(1956). Ideologia e desenvolvimento nacional. Rio de Janeiro: ISEB.

Pinto, Á.V. (1960). Consciência e realidade nacional. Rio de Janeiro: Instituto Superior de Estudos Brasileiros.

Pinto, Á.V.(1997). Sete lições sobre educação de adultos (10. ${ }^{a}$ ed.) São Paulo: Cortez.

Roux, J.(1990). Álvaro Vieira Pinto: nacionalismo e Terceiro Mundo. São Paulo: Cortez.

Schaff, A.(1995). Historia e verdade (6. ${ }^{a}$ ed.). São Paulo: Martins Fontes. 